\title{
PUBLIC PROTECTION OR PRIVATE EXTORTION?
}

\author{
Ethan Bueno de Mesquita* and Catherine Hafer
}

\begin{abstract}
We analyze the strategic interaction between a firm, an extortionary mafia, and a potentially corrupt government. The model identifies several results. First, government spending is not monotonic in revenues. Second, although the firm wants the government to challenge the mafia (it uses the threat of electoral sanctions to induce the government to do so), in equilibrium, the firm does not directly appeal to the government for protection even though it is extorted. The more likely the government is to uncover mafia extortion independent of an appeal from the firm, the more effective the firm's threat of electoral sanction is at motivating the government to invest in law enforcement. This is because the electoral threat to punish failure on the government's part is only a compelling reason to invest in law enforcement when the government actually expects to confront the mafia. This same logic also implies that the relationship between mafia strength and government corruption is somewhat counterintuitive. When the mafia is strong in equilibrium (i.e. pervasive and extorting large fees), the government is not very corrupt. When the mafia is weak, the government is highly corrupt. Finally, an extension shows that if the mafia and government can collude, then the harsher the threatened sanctions against the mafia, the less likely the government is to challenge the mafia because the mafia is more willing to bribe the government.
\end{abstract}

\section{INTRODUCTION}

MAFIAS PLAY many roles in the economy. A major focus of the existing literature is on mafias as relatively benign competitors of the state, supplying comparable services at comparable terms to sustain an underground economy (Alexeev et al., 2003; Bandeira, 2003; Frye and Zhuravskaya, 2000; Gambetta, 1993; Gambetta and Reuter, 1995; Grossman, 1995; Hay and Shleifer, 1998; Johnson et al., 1997; Schelling, 1984; Skaperdas, 2001; Varese, 2001). ${ }^{1}$ Despite the importance of the mafia's role as a competitor to the state, the existence of a strong mafia and the dependence of the economy on its services also carries with it the risk of extortion because a mafia is generally not accountable to the firms under its protection (Konrad and

*Corresponding author: Ethan Bueno de Mesquita, Harris School, University of Chicago, 1155 E. 60th Street, Suite 108, Chicago, IL 60637, USA. E-mail: bdm@uchicago.edu

${ }^{1}$ Some view the mafia and the state as analogous, recognizing not only that the mafia may provide valuable services but also that the state may be corrupt or extortionary itself (Konrad and Skaperdas, 1999; Kugler et al., 2005; Tilly, 1985). 
Skaperdas, 1998). ${ }^{2}$ In decentralized politico-economic environments, economic agents resist predation by engaging in conflict themselves (Hafer, 2006; Skaperdas, 1992), but in more centralized systems with states that have developed their capacity for law enforcement, agents call upon the state to protect them. The state may or may not be willing or able to do so.

A typical example is the behavior of the Calabrian mafia - the 'ndrangheta - in southern Italy. A recent report in The Economist describes how the 'ndrangheta demands "protection money" from local businesses. ${ }^{3}$ Those businesses then have two choices: to pay off the mafia or to appeal to the government for protection. Sometimes, however, the government is not strong enough to protect a business that refuses to pay the mafia. The Economist reports that mafia "killers shot a farmer, setting fire to the car in which they had placed his corpse," because "[t]he farmer had filed complaints against people who had put the squeeze on him." Thus, as a Calabrian prosecutor states, in the competition between governments and mafias, "the strongest makes the rules."

In light of this, we focus on the relationship between the presence of an extortionary mafia and the endogenous, electorally derived incentives for the government to develop and use its capacity for law enforcement. In doing so, we abstract away from the mafia's role as a provider of contract enforcement and revenue protection, focusing on its role as an extortionist. We also abstract away from the question of how the mafia and government emerge as distinct entities. Instead, we take the existence of an extortionary mafia and a (at least partially) democratically accountable government as given (although we do allow for the possibility that the government will drive the mafia out of business).

The mafia in our model engages in a protection racket of the sort pursued by the Calabrian mafia. It demands fees from a firm in exchange for "protection" from the mafia itself. Should the firm fail to pay, the mafia employs force to extract resources from the firm. The firm, however, can appeal to the government for protection from the mafia; if the government is successful, the firm suffers no harm.

The intuition of our argument is as follows. The firm exists under the threat of mafia extortion. Government law enforcement can mitigate the mafia's ability to demand protection payments. One way this can occur is that law enforcement can make illegal activity so costly that it drives the mafia out of business. Even when the mafia is not entirely eliminated, law enforcement can reduce the fees the mafia is able to demand in a protection racket by decreasing the risk of expropriation that a firm faces should it

\footnotetext{
${ }^{2}$ The existence of a mafia may lead to economic inefficiency in other ways as well. Its need to hide its identity and its actions limits its ability to operate efficiently relative to a legitimate state (Baccara and Bar-Isaac, 2005; Smith and Varese, 2001). There is also evidence that it undermines competition, creating numerous monopolies (Braguinsky, 1999).

3“"Business in Calabria: Bullets in the Post," The Economist, June 17-23, 2006, p. 71.
} 
refuse to pay off the mafia. Of course, the weakening of the mafia comes at a price to the firm: taxation. Moreover, the firm also has to worry about government corruption: the government may misappropriate resources rather than spend them on law enforcement. ${ }^{4}$ The firm uses electoral incentives to try to solve this moral hazard problem. ${ }^{5}$

The model identifies several results. First, government spending is not monotonic in revenues. Second, although the firm wants the government to challenge and defeat the mafia (indeed, it uses the threat of electoral sanctions to induce the government to do so), in equilibrium, the firm does not appeal directly to the government for protection even though it is extorted. As a result, if the government cannot detect mafia behavior on its own, the mafia completely dominates the political economy. Moreover, the more likely the government is to uncover mafia extortion independent of an appeal from the firm, the more effectively the firm's threat of electoral sanction motivates the government to invest in law enforcement. This is because the electoral threat to punish failure on the government's part is only a compelling reason to invest in law enforcement when the government actually expects to confront the mafia. This same logic also implies that the relationship between mafia strength and government corruption is somewhat counterintuitive. In particular, when the mafia is strong in equilibrium (i.e. pervasive and extorting large fees), the government is not very corrupt. When the mafia is weak, the government is highly corrupt.

We conclude our analysis with two extensions. In the first, we show how the possibility of collusion between the mafia and the government weakly increases the mafia's success in extorting the firm. Furthermore, we show that the harsher the threatened sanctions against the mafia, the less likely the government is to challenge the mafia because the mafia is more willing to bribe the government. In the second, we show that if the government lacks an independent investigative capacity (relying, instead, on the firm to report mafia activity), then the mafia completely dominates the political economy.

\section{THE MODEL}

There are three players: a firm, a mafia, and a government. At the beginning of the game, the firm controls some resources, the total pre-tax value of which is normalized to 1. Taxes are imposed on those resources and turned over to the government. In the section on "Taxation and Firm Welfare," we show that

\footnotetext{
${ }^{4}$ We initially focus our attention on the effects of the embezzlement of public funds on mafia activity and firm welfare, and in an extension we consider the effects of bribing government officials to neglect their duties. However, corruption can take many other forms with diverse consequences. See Shleifer and Vishny (1993) for a discussion of the effects of the illegal trade in government goods and services with and without embezzlement. Bardhan (1997) and Shleifer and Treisman (2000) survey the effects of corruption on economic development.

${ }^{5}$ For another view of why firms might be unwilling to fund a government when mafia enforcement of contracts is an option, see Sonin (2003).
} 
the firm has induced preferences over the tax rate and so we could think of these preferences as one determinant of an endogenously chosen tax rate. However, in practice, taxation is determined principally by factors other than concerns about law enforcement and the mafia (such as redistribution, effort allocation, provision of other public goods, and so on). Furthermore, in many economies plagued by extortionary mafias, effective taxation is determined in large part by the government's capacity for collecting revenues, rather than by statute. ${ }^{6}$ Therefore, we treat the tax rate, $t$, as exogenous.

The sequence of play is as follows. The government chooses a proportion of the tax revenue collected to commit to law enforcement, $\lambda \in[0,1]$. We will refer to the percentage of government revenues not dedicated to law enforcement $(1-\lambda)$ as the level of government corruption. Neither the firm nor the mafia observe $\lambda$. Next, the mafia either can choose not to become active or it can demand a fee, $\phi$, that the firm must pay to it for protection. If the mafia makes a demand, the firm then decides whether to pay off the mafia. Let $\mu$ be the probability that the firm pays off the mafia. If the mafia makes a demand and the firm does not pay it off, the mafia attempts to extort all of the firm's resources. In that case, the firm appeals to the government for protection; let $\alpha$ be the probability that the government chooses to attempt to disrupt the mafia's activities. If the firm pays off the mafia, it does not appeal to the government and the mafia does not attempt to extort it further. ${ }^{7}$ In this case, Nature reveals the mafia's activities to the government with probability $p$. This reflects the idea that when the firm does not alert the government to the mafia's presence, the government must rely on its own imperfect investigative capacity. In this case, the government can choose, on its own initiative, to engage in law enforcement to attempt to disrupt the mafia's protection racket. Denote by $\gamma$ the government's choice of a probability with which to challenge the mafia, given that the firm pays off the mafia and the government learns of the mafia's activities independently. After the outcome of any conflict is determined, the firm, acting as a voter, chooses whether or not to re-elect the government, which is understood to compete against an otherwise identical challenger. ${ }^{8}$ The probability of re-election $\boldsymbol{\rho}$ can be represented by a finite-dimensional vector specifying the probability of re-election in each observationally distinct (for the firm) situation. There are seven observationally distinct situations under which the firm must decide whether or not to re-elect:

\footnotetext{
${ }^{6}$ For an analysis of these issues see Gehlbach (2007).

${ }^{7}$ One might argue that the mafia faces a commitment problem here; that is, that it could extort the firm for the rest of its resources, even if the firm does pay. However, in equilibrium, the fee the mafia demands is the maximum amount that it can extort from the firm before the firm seeks government protection. If the mafia attempts to take more, it will have to fight the government and suffer the risk of punishment - a risk it prefers to avoid.

${ }^{8}$ The firm is treated as the voter because we take the firm to be broadly representative of economic interests in society. Thus, even if the mafia has a vote, the majority of voters in society have interests that look like the firm's.
} 


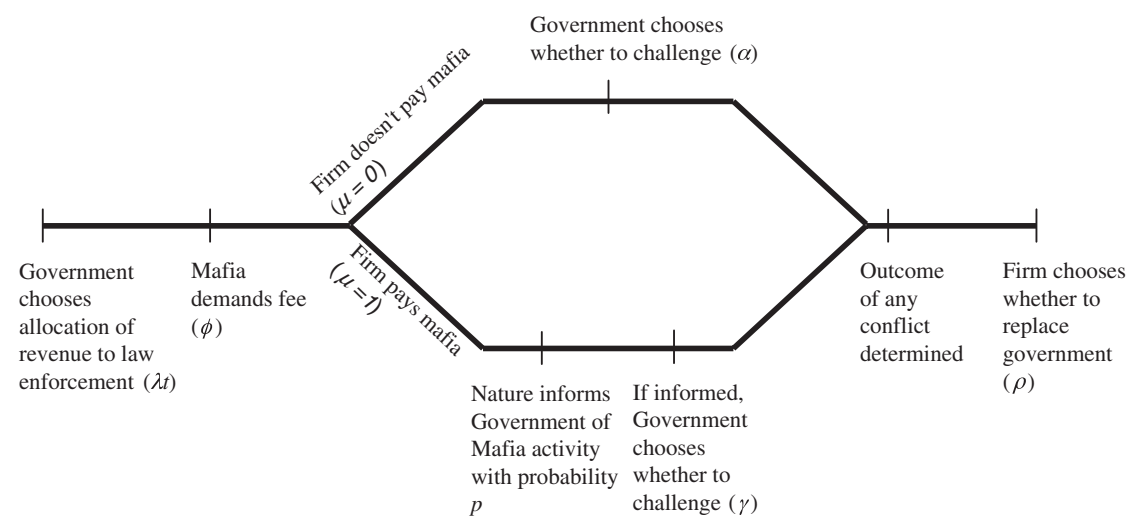

Figure 1. Timeline of the game.

1. The firm pays the mafia, there is conflict between the mafia and the government, and the mafia wins $(M)$.

2. The firm pays the mafia, there is conflict between the mafia and the government, and the government wins $(G)$.

3. The firm pays the mafia and the government does not challenge, so there is no conflict $(N G)$.

4. The firm refuses to pay, there is conflict between the mafia and the government, and the mafia wins $(R M)$.

5. The firm refuses to pay, there is conflict between the mafia and the government, and the government wins $(R G)$.

6. The firm refuses to pay and the government does not challenge, so there is no conflict $(R N G)$.

7. The mafia never makes a demand, so there is no conflict $(N M)$.

The set $\{M, G, N G, R M, R G, R N G, N M\}$ can be thought of as the range of the outcome function, whose arguments include $\mu, \alpha, \gamma, \lambda$, and $t$; to simplify notation, we suppress the functional representation below. Let $\rho_{M}, \rho_{G}, \rho_{N G}$, $\rho_{R M}, \rho_{R G}, \rho_{R N G}$, and $\rho_{N M}$ be the probabilities of re-election that correspond to each of the seven outcomes enumerated above, respectively, where $\boldsymbol{\rho}=\left(\rho_{M}, \rho_{G}, \rho_{N G}, \rho_{R M}, \rho_{R G}, \rho_{R N G}, \rho_{N M}\right) \in[0,1]^{7}$. The timeline of the game is summarized in Figure 1.

\subsection{Payoffs}

The mafia's payoff if it demands fee $\phi$ is the expectation of its net revenue, which is any fee collected minus any cost imposed in defeat. If there is a conflict between the mafia and the government and the mafia loses, the mafia bears an exogenously given cost $k$, which we interpret as the punishment imposed by the government, but gets to keep the fee it has already 
collected. ${ }^{9}$ The probability that the government defeats the mafia when they are in conflict is a function of the government's level of investment in law enforcement $(\lambda t), f:[0,1] \rightarrow(0,1)$. We assume that $f(\cdot)$ is increasing, concave, and satisfies $\lim _{x \rightarrow 0} f^{\prime}(x)=\infty$ :

$$
\begin{aligned}
E\left[u_{M}(\phi) \mid \mu, \lambda, t, \alpha, \gamma, p\right]= & \mu[\phi-\gamma p f(\lambda t) k]+(1-\mu) \\
& \times[(1-\alpha f(\lambda t))(1-t)-\alpha f(\lambda t) k] .
\end{aligned}
$$

The mafia's payoff if it does not make a demand is

$$
E\left[u_{M}(\phi=0)\right]=0 .
$$

The government receives a positive payoff, $R(t)$, if it is re-elected and 0 if it is not re-elected. We assume that $R(\cdot)$ is increasing in the tax rate, that is, the benefit of holding office is increasing in the government's budget. ${ }^{10}$ The government's payoff is the expectation of any tax revenue not spent plus any electoral benefit. Thus, given the level of investment in law enforcement $(\lambda)$ and the probabilities of challenging the mafia if the mafia runs a protection racket $(\gamma$ and $\alpha$ ), the government's expected utility is

$$
\begin{aligned}
E\left[u_{G}(\lambda, \alpha, \gamma) \mid \mu, t, p, \boldsymbol{\rho}\right]= & (1-\lambda) t+\mu\left[\gamma p\left(f(\lambda t) \rho_{G}+(1-f(\lambda t)) \rho_{M}\right)\right. \\
& \left.+(1-\gamma p) \rho_{N G}\right] R(t)+(1-\mu) \alpha\left(f(\lambda t) \rho_{R G}\right. \\
& \left.+(1-f(\lambda t)) \rho_{R M}\right) R(t) .
\end{aligned}
$$

The firm's expected utility is the expectation of the economic resources it controls net of taxes, fees paid, and money extorted:

$$
E\left[u_{F}(\mu, \boldsymbol{\rho}) \mid \lambda, t, \phi\right]=\mu(1-t-\phi)+(1-\mu) \alpha f(\lambda t)(1-t) .
$$

\section{EQUILIBRIUM}

Our solution concept is perfect Bayesian equilibrium (PBE). We refine this equilibrium concept in three ways. First, we assume that players do not play weakly dominated strategies. Second, we assume that the firm chooses from the set of sequentially rational re-election rules the one that maximizes its ex ante expected utility. We adopt this requirement because, as the game ends with an election decision, the firm is indifferent over whether or not to re-elect the government (there are no future actions to be taken). Thus, all reelection rules are sequentially rational. This is the standard approach taken

\footnotetext{
${ }^{9}$ It might seem that increasing $k$, thereby making mafia activity arbitrarily bad for the mafia, must improve firm welfare. Proposition 3 and Corollary 1 make clear that, in an environment in which the government and the mafia might collude, this is not the case.

${ }^{10}$ The idea here is that the government must be made at least weakly better off by having more resources at its disposal. This could be made endogenous in a simple extension with two periods where, in the second period, there was no electoral threat so the government was able to misappropriate everything.
} 
in models of retrospective voting (e.g. Austen-Smith and Banks, 1989; Barro, 1973; Ferejohn, 1986). Finally, because the firm has the same information about the government's actions that the mafia has, there is no reason for the firm to believe it can learn about the government's actions from the mafia. Thus, we assume that it does not update its beliefs about the government's actions based on the mafia's behavior. This implies that the firm has the same beliefs at all information sets.

We refer to a PBE satisfying these restrictions as an equilibrium. We solve for the unique such equilibrium.

\subsection{Whether to Challenge the Mafia}

Because the firm chooses the re-election rule that induces behavior from the government that is good for the firm, in order to determine the optimal reelection rule we need to know how the government responds to electoral pressure and how the mafia responds to government actions. Thus, we defer discussion of the optimal re-election rule until after solving for the rest of the equilibrium behavior.

If the firm refuses to pay off the mafia or if the firm pays off the mafia and the government discovers the mafia's activities, then the government has a choice of whether or not to challenge ( $\alpha$ and $\gamma$, respectively). At this point in the game, the only way in which the decision of whether to challenge can affect the government's payoffs is through its effect on re-election. Hence, the government chooses its probabilities of challenging the mafia to maximize the probability of re-election, given the level of investment in law enforcement $(\lambda t)$ and the re-election rule $\left(\rho^{*}\right)$. With this in mind, we can characterize the government's best-response correspondence for its choices of $\alpha$ and $\gamma$.

Lemma 1. If the firm pays the mafia, the government weakly prefers to challenge the mafia if

$$
\rho_{M}^{*}(1-f(\lambda t))+\rho_{G}^{*} f(\lambda t) \geq \rho_{N G}^{*},
$$

with the preference being strict if the inequality is strict. If the firm refuses to pay the mafia, the government weakly prefers to challenge the mafia if

$$
\rho_{R M}^{*}(1-f(\lambda t))+\rho_{R G}^{*} f(\lambda t) \geq \rho_{R N G}^{*},
$$

with the preference being strict if the inequality is strict.

All proofs are in Appendix A.

\subsection{Paying the Mafia}

Once the firm has paid the mafia, the firm's induced preferences over whether the government challenges $(\gamma)$ at the time of the government's action 
are such that it is expectationally indifferent between the government challenging with certainty $(\gamma=1)$ and the government not challenging $(\gamma=0)$. This does not, of course, mean that firm is indifferent over the government's strategy. Rather, it cares only to the extent that government behavior affects the fee the mafia demands. This intuition is formalized in the following lemma, which is instrumental in solving for equilibrium behavior.

Lemma 2. If the firm has paid the mafia, the firm's preferences over government action $\gamma$ are completely induced by the effects of that action on the mafia's choices.

Because the firm is indifferent over all $\gamma \in[0,1]$ at the time of the government's action, it can credibly commit to any electoral response to that action at an earlier point in the game, and thus can use electoral incentives to elicit the behavior on the part of the government that has the most desirable effect on the behavior of the mafia. Lemma 2 also implies that the firm's decision to pay off the mafia and even the mafia's choice of what fee to demand, conditional on its choosing to enter the market, are independent of $\gamma$.

Now, consider the case where the mafia extorts the firm and the firm refuses to pay. In this case, the firm strictly prefers the government to challenge the mafia. It can induce the government to do so by, for example, promising credibly not to re-elect the government if it fails to challenge and to re-elect with positive probability if it does challenge. Formally, the firm can choose $\left(\rho_{R N G}, \rho_{R G}, \rho_{R M}\right)$ such that $\rho_{R M}^{*}(1-f(\lambda t))+\rho_{R G}^{*} f(\lambda t)>\rho_{R N G}^{*}$. Thus, in equilibrium the government always challenges the mafia when the firm refuses to pay $\left(\alpha^{*}=1\right)$.

The firm will pay the fee named if and only if that fee is smaller than the expected loss associated with not paying it. By comparing the firm's expected utility from paying off the mafia with its expected utility from not doing so, we can find the upper bound on the fee that the mafia can charge such that the firm prefers to pay it off.

Lemma 3. The maximal fee the mafia can extract is $\bar{\phi}=(1-t)(1-f(\tilde{\lambda} t))$, which is decreasing in the firm's beliefs about government spending on law enforcement $(\tilde{\lambda} t)$.

The maximal fee the mafia can extract $(\bar{\phi})$ highlights how government law enforcement spending can mitigate the threat of mafia extortion. When the government invests in law enforcement, the risk to a firm of not paying off the mafia is lowered. This is because high levels of law enforcement spending make it more likely that the government will successfully defend the firm if it refuses to pay off the mafia. Consequently, the fee that the firm is willing to pay (and that the mafia can therefore extract) is decreasing in the firm's beliefs about government spending on law enforcement. 
It is worth noting that this result seems to contrast with existing empirical findings that taxation and mafia extortion are positively correlated (see, e.g., Johnson et al., 1997). However, those empirical findings are crosssectional, while our result should be interpreted as a within-country comparative static. Our model does not account for the many cross-country differences that simultaneously affect both taxation and the presence of the mafia. And, at least anecdotally, our result is consistent with changes that have occurred in Russia in the last decade. In particular, tax revenues have grown while, coincidentally or not, organized crime's hold over the Russian private sector has decreased (Gaddy and Gale, 2005; Sokolov, 2004).

\subsection{The Mafia's Demand}

The mafia has to choose whether or not to run a protection racket and, if it does so, how much to demand from the firm. Clearly, if the mafia runs a protection racket, it will demand the highest fee the firm is willing to pay (i.e. $\bar{\phi}$ ). It will choose to run a protection racket when the net payoff from demanding this fee and risking confrontation with the government is larger than the payoff from exiting the market.

To formalize this, we need the following notation. Let $\tilde{\lambda}$ and $\tilde{\tilde{\lambda}}$, respectively, represent the firm's and the mafia's beliefs about government investment in law enforcement.

\section{Lemma 4. If}

$$
\gamma^{*} p k \leq(1-t) \frac{(1-f(\tilde{\lambda} t))}{f(\widetilde{\tilde{\lambda}} t)},
$$

then the mafia demands $\phi=(1-t)(1-f(\tilde{\lambda} t))$, correctly anticipating that the firm will pay it off. If

$$
\gamma^{*} p k>(1-t) \frac{(1-f(\tilde{\lambda} t))}{f(\widetilde{\tilde{\lambda}} t)},
$$

then the mafia makes no demand, exiting the market.

\subsection{Investment in Law Enforcement}

The government chooses the amount of tax revenues it collects to allocate to law enforcement $(\lambda)$ such that

$$
\lambda \in \arg \max E\left[u_{G}\left(\lambda, \gamma^{*}, \alpha^{*} ; \boldsymbol{\rho}^{*}, \mu^{*}, p, t\right)\right] .
$$

The following result is useful in finding the government's optimal allocation. 
Lemma 5. The government will never choose $\lambda$ such that $\gamma \in(0,1)$.

This lemma implies that we can restrict attention to cases where, if the firm pays off the mafia and the government becomes aware of the mafia's activities, the government never challenges $(\gamma=0)$ or challenges with certainty $(\gamma=1)$. Moreover, if the government never challenges in equilibrium, then it has no incentive to invest in law enforcement because it is never called upon to fight. Likewise, if the mafia makes no demands, the government has no incentive to invest.

In choosing how to allocate tax resources, the government considers several factors. On the one hand, spending tax revenues on law enforcement is costly in terms of foregone misappropriation. On the other hand, investment in law enforcement may affect the government's probability of reelection.

There are three possible effects of electoral incentives on government spending on law enforcement. The voting rule might punish the government for defeating the mafia, be unrelated to whether the government defeats the mafia, or reward the government for defeating the mafia. In the first two cases, the government has no electoral incentive to invest in law enforcement. This, coupled with the desire to misappropriate as much as possible, leads the government not to invest any resources in law enforcement. In the latter case, the government faces a tradeoff between misappropriation and re-election. How these various considerations balance out depends on the level of tax revenues.

Because the case where the firm provides electoral incentives for investing in law enforcement is the only case where the government faces any choice over the division of resources, we analyze this case. Later we demonstrate that the optimal behavior of the firm is to provide such incentives. The proportion of tax revenue the government commits to law enforcement is derived in section A.6 and is stated formally in Lemma 7 in that section. We discuss the intuition below.

For low tax rates, the government allocates revenue to law enforcement until the marginal expected electoral benefit from increasing the probability of victory over the mafia equals the marginal cost of forgone misappropriation. Because the electoral benefit $(R(t))$ is increasing in the tax rate, the optimal allocation to law enforcement is increasing in the tax rate when the optimal allocation is interior. However, if for some tax rates the electoral benefit is sufficiently large, then there can be a corner solution where the government spends all of its revenues on law enforcement.

As long as the tax rate is not too high, the mafia will prefer to collect its fee and risk punishment from the government; however, for sufficiently high tax rates, the fee that the mafia can demand from the firm is too small to warrant such risks. Label the first tax rate for which this is true $\overline{\bar{t}}$ (it is formally characterized in section A.6). In such circumstances, if the government 
chooses a high level of law enforcement, so that the mafia's risk of punishment is high, the mafia will withdraw from the market, making no demand. But if the mafia withdraws, the government's choice to commit resources to law enforcement is not optimal because it is never in conflict with the mafia. In this circumstance, the government should deviate to no investment in law enforcement. But, when it does so, the mafia faces little risk of punishment, and thus wants to demand a fee that leads the firm to pay it off, which again makes the government's resource allocation decision sub-optimal. Thus, for these moderately high tax rates, the government commits fewer resources to law enforcement and the mafia randomizes between demanding the maximal fee that induces the firm to pay and withdrawing from the market, making no demand. This strategy profile limits the mafia's risk of punishment by the government. Furthermore, the government's limited investment in law enforcement is rational because conflict with the mafia occurs relatively rarely (because the mafia sometimes withdraws) but not never.

For very high tax rates, the fee that the mafia can obtain from the firm is too small to warrant risking confrontation with even the weakest government, i.e. one that invests nothing in law enforcement. As such, the mafia withdraws from the market and, hence, the government invests no tax revenues in law enforcement. Label this tax rate $\bar{t}$.

The absolute amount the government spends on law enforcement, the fee charged by the mafia, and the likelihood of the mafia operating its optimal protection racket rather than withdrawing from the market are each represented as a function of the tax rate in Figure 2. ${ }^{11}$

Taxation, Government Corruption, and Law Enforcement. Taxation, in this model, may benefit the firm by increasing law enforcement and thereby weakening the mafia. The question arises, then, whether increasing government funding will actually lead to an increase in law enforcement spending, given the potential for government corruption (which we earlier defined as government revenue not spent on law enforcement). Furthermore, note that in equilibrium the mafia and the firm have correct beliefs about government corruption (i.e. $\tilde{\lambda}=\tilde{\tilde{\lambda}}=\lambda^{*}$ ). ${ }^{12}$

As already discussed, the government, in choosing how much to invest in law enforcement, balances two types of incentives: the temptation to misappropriate tax revenues and the electoral incentives to invest in law enforcement. These electoral incentives come from the firm's threat not to re-elect the government should it fail to challenge and defeat the mafia.

\footnotetext{
${ }^{11}$ Note, in the figure, that, as shown in Lemma 7, the curve $\lambda^{*} t$ is increasing in region A, but we do not know its specific shape.

${ }^{12}$ This is true on and off the path of play because the mafia has only one information set and the firm has the same beliefs at all information sets, since no information is revealed to the firm.
} 


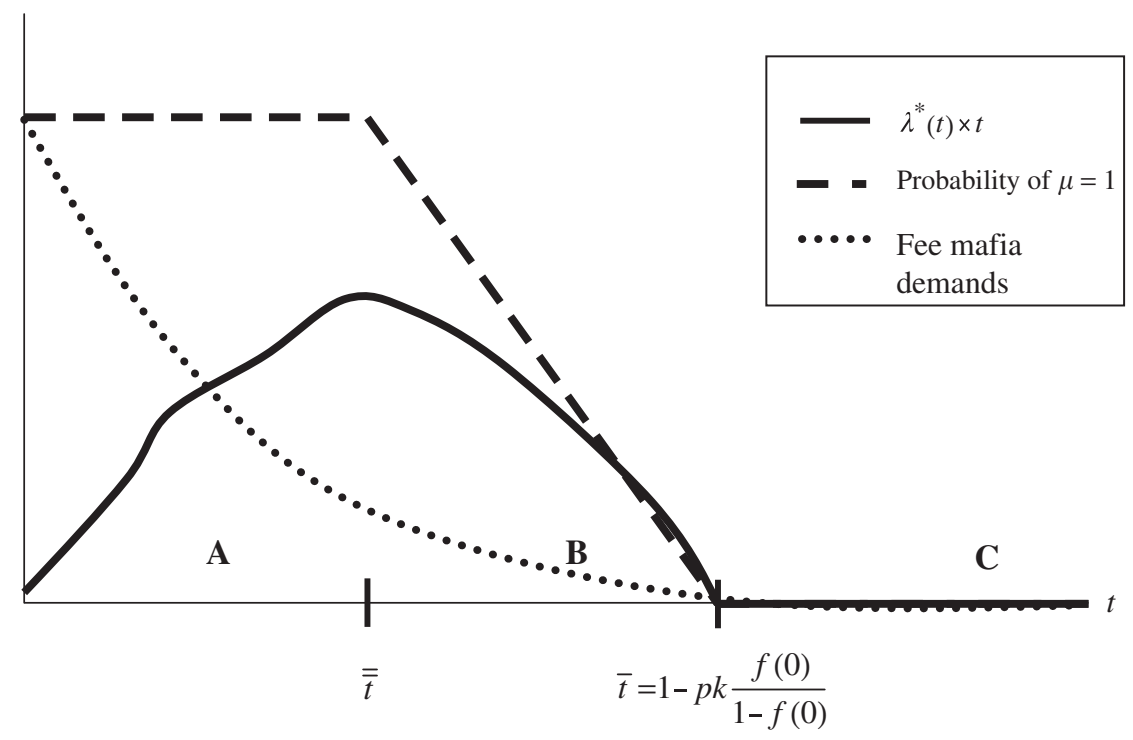

Figure 2. The effect of increasing taxes on law enforcement expenditures, the frequency with which the mafia is paid off, and the fee paid to the mafia, with the equilibrium values $\rho_{G}=1$ and $\rho_{M}=0$ (see Remark 1), and conditions satisfied for the possibility of an interior $\lambda$ (see Lemma 7).

As taxes change, the marginal payoff from government misappropriation stays constant. However, the electoral incentives change in two ways. First, as taxes increase, the value of re-election increases directly (we refer to this as the direct electoral effect). Second, for a fixed percentage $(\lambda)$, as taxes go up the benefit to the mafia of running a protection racket goes down. This is true both because there is less money to extort from the firm and because the risk of conflict is higher. As a result of this deterrence effect, increased taxation can actually decrease incentives for the government to invest in law enforcement. Thus, the direct electoral effect of taxation and the deterrence effect of taxation push incentives for government spending on law enforcement in different directions.

In region A of Figure 2, government spending on law enforcement is increasing in the tax rate. In this region, the firm always pays off the mafia (i.e. there is no deterrence), hence the probability of conflict with the mafia is constant. Moreover, as the tax rate increases, the direct electoral effect implies that the benefit of re-election increases. Hence, as tax revenues grow, the overall marginal benefit of spending on law enforcement increases.

Once taxes become high enough (region B), the level of corruption increases as tax revenue increases. This is because, as taxes increase in this range, the threat of conflict with the government looms large, hence the mafia makes demands of the firms less frequently. That is, as taxes increase 
in this range, the deterrence effect weakens electoral incentives to invest in law enforcement because conflict between the government and mafia becomes less frequent. In fact, in this range, corruption is increasing so fast that total expenditures on law enforcement are actually decreasing in the level of taxation - the more resources the government has, the fewer resources (in absolute, not just percentage, terms) it spends on law enforcement.

Finally, when taxes are high enough (region C), the mafia cannot extract a fee that makes being in business worthwhile, so the government is never called on to challenge the mafia, and therefore it misappropriates all tax revenues, spending nothing on law enforcement.

It follows that the absolute level of spending on law enforcement $(\lambda t)$ is not monotonic in the tax rate. Particularly surprising is that there are tax rates for which, as government revenues increase, government expenditures decrease.

Proposition 1. Government spending on law enforcement $(\lambda t)$ is not monotonic in the level of taxation. It is increasing in region $\mathrm{A}$, decreasing in region $\mathrm{B}$, and zero and flat in region $\mathrm{C}$.

Taxation and Mafia Viability. The dashed line in Figure 2 shows that the frequency with which the mafia chooses to be in business is weakly decreasing in the tax rate. When taxes are low (in region A), the mafia runs a successful protection racket in the sense that the firm always pays the fee the mafia demands. However, government policy in this region does have an effect on the mafia. In particular, government investment in law enforcement and the threat of punishment decrease the mafia's fee. Thus, in this region the firm uses electoral pressure to successfully limit the strength, if not the ubiquity, of the mafia, by pressuring the government to spend tax resources on law enforcement. As taxes increase even further, into region $\mathrm{B}$, the mafia is weakened, in the sense that it sometimes withdraws from the market to avoid a confrontation with the government. Finally, if taxes become high enough (region C), the mafia is entirely eradicated. In order to achieve this outcome, the firm must turn over so much money to the state in the form of taxes that the fee that the mafia is able to demand is not sufficient to overcome the risk of punishment that the mafia faces, even when the government invests nothing in law enforcement.

The level of taxation that drives the mafia out of business is $\bar{t}=1-k p[f(0) /(1-f(0))]$. Three comparative statics are evident. First, $\bar{t}$ is decreasing in the government's natural advantage relative to the mafia $(f(0))$. That is, in societies where existing norms and non-governmental institutions strengthen the government relative to mafias, it is relatively inexpensive to drive the mafia out of business. Second, $\bar{t}$ is decreasing in $k$ 
(but see Proposition 3 for a result suggesting that increasing $k$ is not a "free lunch" for the firm). The larger the penalty the government is able to impose, the easier it is to eradicate the mafia. Third, $\bar{t}$ is decreasing in $p$. The more likely the government is to discover independently the mafia's activities, the more likely the government is to defeat the mafia. This is true because the electoral reward associated with defeating the mafia in equilibrium insures that the government confronts the mafia whenever it learns of extortionary activity. Furthermore, as a result of this increased likelihood of conflict, the government invests more resources into law enforcement. Thus extortion is a less-rewarding activity for the mafia in equilibrium when tax rates are higher or when the government is more likely to learn of the mafia's activities.

Proposition 2. The frequency with which the mafia runs a protection racket rather than not entering the market is weakly decreasing in the tax rate, with the mafia entirely removed from the market if taxes are high enough. The level of taxation necessary to force the mafia to withdraw is decreasing in the government's natural advantage relative to the mafia $(f(0))$, in the penalty the government is able to impose on the mafia $(k)$, and in the probability the government independently uncovers the mafia's activities $(p)$.

Taxation and Firm Welfare. Propositions 1 and 2 suggest that from the firm's perspective, there are two possible types of tax rates that best mitigate the effects of the mafia on firm welfare. In the first case, the government is cash starved (taxes are low) but not corrupt, and the mafia runs a protection racket all the time. In the second case, the government is well funded (taxes are high), which leads to high levels of government corruption but to a weaker mafia protection racket (i.e. the mafia can only successfully demand payment from the firm some of the time, and when it does pay, the fee is lower).

In the case where the government is cash starved, the tax rate lies in region A of Figure 2. In this region, increasing taxation has competing effects on firm welfare. On the one hand, as taxes increase, law enforcement spending increases. This decreases the fee the mafia can demand. On the other hand, increased taxation imposes a direct decrease on firm revenue.

In the case where the government is well funded, the tax rate lies in region $\mathrm{B}$ of the figure. Here, increasing taxes has three effects on firm welfare. First, it has the direct effect of taking away resources from the firm through taxation. Second, it changes the probability that the mafia stays in business and extracts its fee. As shown in the proof of Proposition 2, this effect is positive - increasing taxes decreases the probability that the mafia remains in business, which increases the expected revenues left for the firm. In contrast, increasing taxes decreases total spending on law enforcement, which increases the fee the mafia can demand, conditional on staying in business, which diminishes the firm's expected resources. 
Whether the tax rate that leaves the firm with the most resources (net of taxes and mafia activity) lies in region A or region B depends on parameter values. The key point, however, is that the firm's induced preferences differ from standard intuitions. It is not simply the case that the firm would want to pay off the mafia when it is strong and fund the government when it is efficient and honest. Indeed, when the firm would like a high level of taxation, the government is particularly inefficient at providing law enforcement because it is highly corrupt. Moreover, even when the firm would like a high tax rate, generally the mafia persists, albeit at a lower level of activity. The firm would be willing to pay high taxes and endure government corruption in order to force the mafia to charge lower fees.

\subsection{Optimal Electoral Incentives}

Having solved for the optimal behavior of the mafia and the government, given an electoral rule, we can now return to determining the firm's optimal voting rule.

From Lemma 3 and the fact that both the mafia and the firm have correct beliefs in equilibrium, if the mafia expects its demands to be met by the firm, then the fee the mafia demands is decreasing in the government's equilibrium investment in law enforcement $\left(\lambda^{*} t\right)$. Hence, the firm wants to induce the government to invest as much as possible in law enforcement. The firm also wants to induce the highest possible probabilities of the government's challenging the mafia ( $\alpha$ and $\gamma$ ), both because the government has greater incentive to invest in law enforcement if it anticipates confronting the mafia more often and because the probability that the government challenges the mafia increases the probability that the government defeats the mafia, all else equal.

Lemma 2 implies that the firm can credibly commit ex ante to any electoral response to induce the government to challenge the mafia $(\gamma>0)$ when the firm pays the mafia. Lemma 2 also implies that the firm's optimal choice of electoral behavior depends not only on the government's response to the incentives created but also on the incentives the response creates for the mafia.

In light of these conditions, what re-election rule will the firm adopt? First, recall that the firm induces the government to challenge the mafia when the firm refuses to pay $\left(\alpha^{*}=1\right)$. As a result, the mafia prefers either to demand a fee the firm will pay or to stay out of the market. Also notice that the reelection probability conditional on the government not challenging when the firm has paid the mafia off $\left(\rho_{N G}\right)$ affects the government's choice of whether to challenge, but does not directly enter into the government's choice of investment in law enforcement. Next, consider the electoral responses when the firm has paid the mafia and the government loses a conflict with the mafia $\left(\rho_{M}\right)$ or wins a conflict with the mafia $\left(\rho_{G}\right)$. Government investment in 
law enforcement $\left(\lambda^{*}\right)$ is weakly increasing in $\rho_{G}$ and weakly decreasing in $\rho_{M}$. That is, if the government is rewarded for winning and punished for losing, it has incentives to invest in law enforcement. Because the firm wants government law enforcement spending to be as large as possible, it will provide electoral incentives for government victory. Thus, the firm wants to make $\rho_{G}-\rho_{M}$ as large as possible, conditional on also inducing the government to challenge the mafia. Ideally, then, from the firm's perspective, it would choose $\rho_{G}=1, \rho_{M}=0$, and would successfully induce the government to challenge. Can the firm do this?

Assume that $\rho_{G}=1$ and $\rho_{M}=0$. When will the government challenge? First, notice that, from equation (A1), if $\rho_{N G}<f(0)<1$, then the government challenges no matter what it invests in law enforcement. Hence, the firm can always induce the government to challenge. Indeed, it may be able to do so for values of $\rho_{N G}$ even greater than $f(0)$. If the government knows that it will not challenge, then it will not invest any resources in law enforcement. Hence, the payoff to the government from not challenging is $t+\rho_{N G} R(t)$. The payoff from challenging is $\left(1-\lambda^{*}\right) t+p f\left(\lambda^{*} t\right) R(t)+(1-p) \rho_{N G} R(t)$. Hence, the government will challenge if $\rho_{N G}<f\left(\lambda^{*} t\right)-\left(\lambda^{*} t\right) /(p R)$. We summarize this argument in the following remark.

Remark 1. The firm chooses a re-election rule in which it (i) re-elects the government with certainty if the government challenges the mafia and wins; (ii) does not re-elect the government if it challenges and loses; and (iii) re-elects the government with a probability of no more than $\max \left\{f(0), f\left(\lambda^{*} t\right)-\left(\lambda^{*} t\right) /(p R)\right\}$ if the government does not challenge the mafia, given in each case that the firm pays the mafia.

Remark 1 shows that the firm adopts the intuitive electoral strategy. It rewards the government electorally if it challenges the mafia and wins and punishes the government if it fails to challenge or challenges but loses. The credible commitment to this retrospective voting rule provides the government with incentives to invest in law enforcement and challenge the mafia.

Interestingly, there is a disparity between the private and public aspects of the firm's response to mafia activity. Although, in equilibrium, the firm will not report the mafia to the government when it is being extorted, it does reward the government electorally for taking a tough stand against the mafia. As a result, it is in the government's interest, in equilibrium, to learn of the mafia's activities, all else equal.

\section{EXTENSIONS}

\subsection{The Possibility of Collusion}

A common theme in the literature on crime and government corruption that we have not yet touched on is the bribery of government officials to overlook 
or ignore criminal acts. In this section, we explore the implications of introducing the possibility of collusion between the mafia and the government and the effectiveness of electoral sanctions in controlling such collusion. ${ }^{13}$

Consider an extension in which, at the time when the government chooses whether or not to challenge the mafia, the mafia and the government can collude to prevent the government from breaking up the mafia's protection racket. In particular, let the order of play be as before, except that after the firm chooses whether or not to pay the mafia, if the government is aware of the mafia's activities, it can demand a bribe from the mafia in exchange for not challenging. Label the government's demand after the firm has refused to pay off the mafia $\beta_{R}$, and the government's demand after the firm has paid off the mafia (and the government has discovered the mafia independently) $\beta_{P}$. Further suppose that any such collusive agreement is binding (i.e. abstract away from any commitment problems).

Paying such a bribe will only be in the mafia's interest if it is cheaper than the mafia's expected loss from fighting the government $(f(\tilde{\lambda} t) k)$. Furthermore, the government will only accept the bribe if its value is greater than the expected electoral reward from conflict.

The firm wants the government to challenge the mafia and wants investment in law enforcement to be as high as possible, since this decreases both the probability the firm will have to pay the mafia and the size of the fee if it does have to pay the mafia. As before, the government will not invest at all if it does not anticipate challenging the mafia. Thus, the firm's first priority is to convince the government to challenge after the firm has paid off the mafia. That is, the firm must choose a re-election rule such that challenging is better than taking a bribe for the government:

$$
\left(f(\lambda t) \rho_{G}+(1-f(\lambda t)) \rho_{M}\right) R(t) \geq \rho_{N G} R(t)+f(\tilde{\lambda} t) k,
$$

where $f(\tilde{\lambda} t) k$ is the bribe the government demands. Once the firm has successfully deterred bribery, it also wants its electoral rule to give the government incentives to invest in law enforcement.

Given this, the optimal voting rule depends on parameter values. First, consider the case where the rewards of re-election to the government are large relative to the punishment the government can impose on the mafia $(R(t)>k)$. In this case the government is disinclined to forgo re-election, which means the minimum acceptable bribe is high. Moreover, the mafia is not particularly afraid of conflict, so it is not particularly willing to bribe the government. Here, then, the intuitive electoral strategy is enough to deter bribery. If the firm rewards the government for challenging and winning $\left(\rho_{G}=1\right)$ and punishes the government for challenging and losing $\left(\rho_{M}=0\right)$ or

\footnotetext{
${ }^{13}$ Whereas in other models the penalty for accepting bribes is exogenously fixed (Basu et al., 1992; Bowles and Garoupa, 1997; Garoupa and Jellal, 2002; Kugler et al., 2005; Polinsky and Shavell, 2001), in ours it is determined endogenously by the firm's equilibrium voting behavior.
} 
for failing to challenge $\left(\rho_{N G}=0\right)$, then the inequality in condition (2) will hold and bribery will not occur.

At the opposite end of the spectrum, consider a situation in which reelection is not very valuable, the threat of punishment is large, and the government is very strong relative to the mafia $(R(t)<f(0) k)$. Here the government is quite open to being bribed relatively cheaply and the mafia wants to avoid conflict and so is quite willing to pay a bribe. In this case there is nothing the firm can threaten to avoid the mafia's bribing the government.

Most interesting is the interim case, where it is not trivial for the firm to deter bribery, but it is also not impossible [i.e. $R(t) \in(k f(0), k)$ ]. Here, choosing a re-electoral rule that rewards the government for challenging and succeeding $\left(\rho_{G}=1\right)$ and punishes the government for not challenging when appealed to $\left(\rho_{N G}=0\right)$ is consistent with both the goals of deterring bribery and encouraging investment in law enforcement. However, there may be a tension between these two goals when it comes to what to do should the government challenge but fail. Rewarding the government for challenging, even if it fails $\left(\rho_{M}=1\right)$, increases the minimal acceptable bribe, making it more likely the mafia will not bribe the government and a challenge will occur. However, this electoral strategy also implies that the government has no incentive to invest in law enforcement $(\lambda=0)$, because it will be rewarded just for trying, regardless of performance. Thus, the firm must find a middle ground, rewarding the government probabilistically should it challenge and fail (i.e. $0<\rho_{M}<1$ ). Note that this strategy is significantly different from that found in the model without collusion, where the firm always punishes failure.

Proposition 3. If $R(t)>k$, then no bribery occurs in equilibrium, the level of investment in law enforcement is positive, and the government is re-elected only if it successfully challenges the mafia. If $R(t) \in(k f(0), k)$, then no bribery occurs in equilibrium, the level of investment in law enforcement is positive but lower, and the government is re-elected with positive probability if it challenges the mafia and with certainty if it wins that challenge. If $R(t)<k f(0)$, then in equilibrium bribery takes place with certainty and the government never challenges the mafia.

It is worth noting one additional implication of this analysis. We have taken the level of punishment that the government can impose on the mafia $(k)$ to be an exogenous parameter throughout the analysis. Thus, it might appear that by increasing the government's capacity for punishment, the firm can costlessly diminish the power and prevalence of the mafia. Proposition 3 demonstrates that this is not true. In particular, as the punitiveness of government punishment increases, the mafia is increasingly willing to pay bribes. Consequently, an increase in $k$ can lead to an increase in bribery and 
a decrease in government law enforcement spending, both of which are bad for the firm. Hence, if the firm were in a position to choose the level of punishment that the government can impose on the mafia, it surely would not choose to make it arbitrarily large.

Corollary 1. The likelihood of bribery and the level of corruption are weakly increasing in the severity of the punishment the government can impose on the mafia $(k)$.

\subsection{The Absence of Government Investigative Capacity}

An instructive question within the context of our model is whether it is important that the government have the independent ability to challenge the mafia even if the firm pays off the mafia rather than soliciting the government's help. What, for instance, would happen if the government could engage in conflict with the mafia only if appealed to by the firm? This would be equivalent to assuming that the government could not independently discover the mafia's activity (i.e. $p=0$ and therefore $\gamma=0$ ).

If the government does not have the capacity to challenge the mafia on its own initiative, then regardless of the tax rate or investment in law enforcement, the firm will pay off the mafia, and the government will have no role. That is, if the government must rely on firm reports of mafia activity, then the economy is entirely dominated by the mafia.

To see why, observe that the expected utilities in this modified game are identical to those in the original game, so both the firm's strategy with respect to hiring the mafia and the mafia's expected utility (evaluated at $\gamma=0$ ) are the same. The key point is that, on the equilibrium path, if the mafia expects that the government will not challenge unless directly appealed to, it demands a fee the firm is willing to pay. Hence, the government never actually challenges the mafia in equilibrium, so it has no incentive to invest in law enforcement and the mafia, therefore, can extract everything from the firm.

Proposition 4. If the government cannot challenge the mafia unless appealed to by the firm (i.e. $\gamma$ is restricted to be 0 ), the game has a unique equilibrium in which the mafia extracts fees from the firm and the government spends no resources on law enforcement.

\section{CONCLUSION}

The presence of mafias in the political economy creates the possibility of extortion. This threat of extortion, we have argued, has important implications for the actions of firms and the government. 
The model identifies several results. First, government spending is not monotonic in revenues. Second, although the firm wants the government to challenge and defeat the mafia (indeed, they use the threat of electoral sanctions to induce the government to do so), in equilibrium, the firm does not directly appeal to the government for protection even though it is extorted. As a result, if the government cannot detect mafia behavior on its own, the mafia completely dominates the political economy. Moreover, the more likely the government is to uncover mafia extortion independent of an appeal from the firm, the more effectively the firm's threat of electoral sanction motivates the government to invest in law enforcement. This is because the electoral threat to punish failure on the government's part is only a compelling reason to invest in law enforcement when the government actually expects to confront the mafia. This same logic also implies that the relationship between mafia strength and government corruption is somewhat counterintuitive. In particular, when the mafia is strong in equilibrium (i.e. pervasive and extorting large fees), the government is not very corrupt. When the mafia is weak, the government is highly corrupt.

Our modeling approach suggests a variety of avenues for future work. We consider a simple version of collusion between governments and mafias here. However, other forms of collusion might also be fruitfully explored in a similar framework. For instance, governments might have an incentive to "hold up" firms in exchange for law enforcement protection from an extortionist mafia. Such incentives would be further exacerbated if the costs governments bear for taxing different firms vary across firms or industries (Gehlbach, 2007). If such rent extraction has efficiency implications, this might provide incentives for firms to sell themselves to the government, providing government officials with an equity stake in the firm in order to mitigate the hold-up problem. Similarly, one might think the mafia could choose directly to engage in conflict with the government, to try to defeat the government before the fact, thereby making the firm even more vulnerable (Dal Bó et al., 2006).

Another possibility would be to consider the effect of the presence of a mafia on new firms' willingness to enter the market. Suppose, for instance, that there is a tax rate that is low enough that the mafia's demands are always met (region A). Imagine that there is a firm that would like to enter the market at that tax rate in the absence of a mafia. However, the presence of the mafia might be enough to deter that firm. The mafia could thereby diminish growth. It might also be the case in such an environment that, if several firms were to enter at once, tax revenues would increase enough to shift the equilibrium to one where the mafia was much less prevalent (akin to region $\mathrm{C}$ in our model). Thus, one might think that the presence of the mafia might lead to incentives for several firms to enter together (and for the government to foster such coordination). Such an extension would surely 
have further implications for the level of corruption, mafia extortion, and the socially optimal tax rate.

Thus, within the context of the relationship between states, firms, and extortionary mafias, there are a rich variety of theoretical questions to be explored within the basic framework we propose. We leave them for future research.

\section{APPENDIX A. PROOFS}

\section{A.1 Proof of Lemma 1}

We focus on the case where the firm has paid the mafia $(\gamma)$. From the government's perspective, the other case is symmetric.

The government's expected utility from challenging with certainty, given that the firm has paid and the government has learned of the mafia's activities, is

$$
\begin{aligned}
E\left[u_{G}\left(\gamma=1, \boldsymbol{\rho}^{*}, \lambda, t \mid \mu=1\right)\right]= & (1-\lambda) t+f(\lambda t) \rho_{G}^{*} R(t) \\
& +(1-f(\lambda t)) \rho_{M}^{*} R(t) .
\end{aligned}
$$

That is, the government's expected utility from challenging is the revenue it retains, plus the probability it defeats the mafia times the probability it is reelected given that it defeats the mafia times the benefit of re-election, plus the probability it loses times the probability it is re-elected given that it loses times the benefit of re-election. The government's expected utility from never challenging when the firm pays is the revenue it retains plus the probability it is re-elected given that it does not challenge times the benefit of re-election:

$$
E\left[u_{G}\left(\gamma=0, \boldsymbol{\rho}^{*}, \lambda, t \mid \mu=1\right)\right]=(1-\lambda) t+\rho_{N G}^{*} R(t) .
$$

Comparing these, we find that the government's best response correspondence is

$$
\gamma^{*}\left(\lambda, t, \boldsymbol{\rho}^{*} ; \cdot\right)= \begin{cases}1 & \text { if } \rho_{M}^{*}(1-f(\lambda t))+\rho_{G}^{*} f(\lambda t)>\rho_{N G}^{*} \\ \gamma^{\prime} \in[0,1] & \text { if } \rho_{M}^{*}(1-f(\lambda t))+\rho_{G}^{*} f(\lambda t)=\rho_{N G}^{*} \\ 0 & \text { if } \rho_{M}^{*}(1-f(\lambda t))+\rho_{G}^{*} f(\lambda t)<\rho_{N G}^{*} .\end{cases}
$$

Similarly, the government's best response when the firm refuses to pay the mafia is

$$
\alpha^{*}\left(\lambda, t, \boldsymbol{\rho}^{*} ; \cdot\right)= \begin{cases}1 & \text { if } \rho_{R M}^{*}(1-f(\lambda t))+\rho_{R G}^{*} f(\lambda t)>\rho_{R N G}^{*} \\ \alpha^{\prime} \in[0,1] & \text { if } \rho_{R M}^{*}(1-f(\lambda t))+\rho_{R G}^{*} f(\lambda t)=\rho_{R N G}^{*} \\ 0 & \text { if } \rho_{R M}^{*}(1-f(\lambda t))+\rho_{R G}^{*} f(\lambda t)<\rho_{R N G}^{*}\end{cases}
$$




\section{A.2 Proof of Lemma 2}

We compare the firm's expected utilities associated with $\gamma=1$ and $\gamma=0$, respectively.

$$
\begin{aligned}
E\left[u_{i}(\gamma=1, \mu=1), \cdot\right] & =(1-f(\tilde{\lambda} t))(1-t-\phi)+f(\tilde{\lambda} t)(1-t-\phi) \\
& =1-t-\phi=E\left[u_{i}(\gamma=0, \mu=1), \cdot\right]
\end{aligned}
$$

\section{A.3 Proof of Lemma 3}

If the firm pays off the mafia, its expected payoff is $1-t-\phi$. Given that the government challenges the mafia in equilibrium if the firm refuses to pay the mafia, the firm's expected payoff is $f(\tilde{\lambda} t)(1-t)$, where $\tilde{\lambda}$ represents the firm's beliefs about the government's level of investment in law enforcement. ${ }^{14}$ Thus, the firm will pay off the mafia if and only if

$$
\phi \leq(1-t)(1-f(\tilde{\lambda} t)) \equiv \bar{\phi} .
$$

\section{A.4 Proof of Lemma 4}

If the mafia chooses $\phi$ such that the firm is willing to pay it off, its expected utility is

$$
E\left[u_{M}\left(\phi \leq \bar{\phi} ; \widetilde{\tilde{\lambda}}, \gamma^{*}, t, p\right)\right]=\phi-\gamma^{*} p f(\widetilde{\tilde{\lambda}} t) k,
$$

where $\widetilde{\tilde{\lambda}}$ represents the mafia's beliefs about government spending on law enforcement. Because the above payoff is increasing in $\phi$, if the mafia is going to choose a fee that induces the firm to pay it off, it will clearly choose the highest such fee $(\phi=\bar{\phi})$.

The mafia's next alternative is to charge a fee high enough that the firm does not pay it off. In this case, the mafia will attempt to extort all of the firm's resources, yielding expected utility:

$$
E\left[u_{M}\left(\phi>\bar{\phi} ; \widetilde{\tilde{\lambda}}, \alpha^{*}, \alpha^{*}, t\right)\right]=(1-f(\widetilde{\tilde{\lambda}} t))(1-t)-f(\widetilde{\tilde{\lambda}} t) k .
$$

Note that demanding a fee of $\bar{\phi}$, which the firm will pay, dominates demanding a higher fee and having to attempt to extort the firm. Thus, the mafia will never demand more than the firm is willing to pay.

The mafia's final option is to make no demand, exiting the market. Its payoff in that case is 0 . Comparing these expected utilities, and substituting for $\bar{\phi}$, the mafia prefers to demand its optimal fee rather than exit the market

\footnotetext{
${ }^{14}$ In equilibrium, the firm's beliefs are degenerate; thus, to simplify notation, we summarize the firm's beliefs with the value of $\lambda$ to which it assigns probability one.
} 
if and only if its expected punishment is less than the total fees it collects:

$$
\gamma^{*} p f(\widetilde{\tilde{\lambda}} t) k<\bar{\phi}=(1-t)(1-f(\tilde{\lambda} t))
$$

\section{A.5 Proof of Lemma 5}

$$
\begin{aligned}
E\left[u_{G}(\lambda, \cdot)\right]= & (1-\lambda) t+\left[\left(1-\mu^{*}(\cdot)\right)\left((1-f(\lambda t)) \rho_{M}^{*}(\cdot)+f(\lambda t) \rho_{G}^{*}(\cdot)\right)\right. \\
& +\mu^{*}(\cdot)\left(p \gamma^{*}(\cdot)\left((1-f(\lambda t)) \rho_{M}^{*}(\cdot)+f(\lambda t) \rho_{G}^{*}(\cdot)\right)\right. \\
& \left.\left.+\left(1-p \gamma^{*}(\cdot)\right) \rho_{N G}^{*}(\cdot)\right)\right] R(t) .
\end{aligned}
$$

From equation (A1), the government's choice of whether or not to challenge the mafia given that the firm has paid the mafia off and the government has become aware of the mafia's activities $(\gamma)$ is a function of the government's resource allocation decision $(\lambda)$. There are two cases to consider:

1. $\rho_{N G}<(1-f(\lambda t)) \rho_{M}+f(\lambda t) \rho_{G}$.

2. $\rho_{N G} \geq(1-f(\lambda t)) \rho_{M}+f(\lambda t) \rho_{G}$.

Because $f(\lambda t)$ is increasing in $\lambda$, we know from equation (A1) that in case 1 , $\gamma=1$, regardless of $\lambda$.

Now consider case 2. There are two possibilities consistent with case 2. From equation (A1) we know that if the inequality defining case 2 is strict, then $\gamma=0$. Lemma 4 implies that if $\gamma=0$, then $\lambda=0$. As we will demonstrate in Remark 1, in equilibrium $\rho_{M}=0$ and $\rho_{G}=1$. Thus, if the inequality defining case 2 holds for some $\lambda>0$, then it must hold strictly for $\lambda=0$. Thus, one possibility in case 2 is that the government chooses $\gamma=0$ and $\lambda=0$, yielding an expected utility

$$
E\left[u_{G}(\lambda=0, \gamma=0)\right]=t+\rho_{N G} R(t) .
$$

The other possibility is that the condition defining the case holds with equality for some $\lambda>0$. In this case, equation (A1) implies that the government will choose any $\gamma \in(0,1)$, in which case the government's expected utility is

$$
\begin{aligned}
E\left[u_{G}(\lambda>0, \gamma \in(0,1))\right]= & (1-\lambda) t+p \gamma\left((1-f(\lambda t)) \rho_{M}+f(\lambda t) \rho_{G}\right) R(t) \\
& +(1-p \gamma) \rho_{N G} R(t) .
\end{aligned}
$$

Note from equation (A1) that if $\gamma \in(0,1)$, then $\rho_{N G}=(1-f(\lambda t)) \rho_{M}+$ $f(\lambda t) \rho_{G}$. This implies that we can rewrite the expected just calculated as:

$$
E\left[u_{G}(\lambda>0, \gamma \in(0,1))\right]=(1-\lambda) t+\rho_{N G} R(t) .
$$


Consider, now, the deviation from $(\lambda>0, \gamma \in(0,1))$ to $(\lambda=0, \gamma=0)$. We have that

$$
E\left[u_{G}(\lambda=0, \gamma=0)\right]=t+\rho_{N G} R(t),
$$

which is clearly larger than $E\left[u_{G}(\lambda>0, \gamma \in(0,1))\right]$. Hence, if $\lambda>0$, then $\gamma \notin(0,1)$. Moreover, if $\gamma=0$, then $\lambda$ must be 0 . Thus, if $\lambda>0$, then $\gamma=1$.

\section{A.6 Derivation of $\lambda^{*}$}

Because (i) mafia and firm beliefs must be correct on the path, (ii) the mafia only has one information set, and (iii) the firm's beliefs are the same at all information sets, it must be that $\tilde{\lambda}=\tilde{\tilde{\lambda}}=\lambda$ at all information sets. From Lemma $5, \lambda>0$ implies $\gamma=1$, which, from equation (A1), implies that $\rho_{N G}<(1-f(\lambda t)) \rho_{M}+f(\lambda t) \rho_{G}$. Recall from equation (A4) that the mafia demands fee $\bar{\phi}$ only if

$$
k<\frac{(1-t)}{p \gamma} \frac{\left(1-f\left(\lambda^{*} t\right)\right)}{f\left(\lambda^{*} t\right)} .
$$

If the mafia makes no demand then $\lambda=0$. Hence, if $\lambda>0$ we can further restrict attention to cases where equation (A4) is satisfied. Given that $\gamma=1$ if $\lambda>0$, the government's expected utility is given by

$$
E\left[u_{G} \mid \lambda, \mu=1, \cdot\right]=(1-\lambda) t+p\left[(1-f(\lambda t)) \rho_{M}+f(\lambda t) \rho_{G}\right] R(t) .
$$

At an interior solution, the optimal level of investment in law enforcement, labeled $\lambda^{\prime}$, satisfies the following first-order condition:

$$
f^{\prime}\left(\lambda^{\prime} t\right)-\frac{1}{p\left(\rho_{G}-\rho_{M}\right) R(t)}=0 .
$$

We must also consider corner solutions. The assumption that $\lim _{x \rightarrow 0} f^{\prime}(x)=\infty$ rules out $\lambda^{\prime}=0$. However, if $f^{\prime}(\lambda t)>1 /\left[p\left(\rho_{G}-\rho_{M}\right) R(t)\right]$, for all $\lambda \leq 1$, then there is a corner solution at $\lambda^{\prime}=1$.

Lemma 6. At an interior solution $\lambda^{\prime} t$ is strictly increasing in $t$.

Proof. The right-hand side of equation (A6) is decreasing in $t$. Thus, the lefthand side must also be decreasing in $t$. Because $f$ is concave, this implies that $\lambda^{\prime} t$ is increasing.

$\lambda^{\prime}$ is the optimal choice of investment in law enforcement, given that the government challenges. However, no investment in law enforcement $(\lambda=0)$ 
could be optimal if the government chooses not to challenge. In order to determine when $\lambda^{\prime}$ is preferred to $\lambda=0$, we need to consider two cases.

Case 1: $\rho_{N G}<(1-f(0)) \rho_{M}+f(0) \rho_{G}$.

In this case, if the government chooses to deviate from $\lambda=\lambda^{\prime}$ to $0, \gamma$ nonetheless remains equal to 1 . From the concavity of $f(\cdot)$ and the definition of an optimum, it follows that $\lambda=0$ cannot be optimal in this case unless $\lambda^{\prime}$ is itself equal to 0 , which is never true.

Case 2: $\rho_{N G} \in\left((1-f(0)) \rho_{M}+f(0) \rho_{G},\left(1-f\left(\lambda^{\prime} t\right)\right) \rho_{M}+f\left(\lambda^{\prime} t\right) \rho_{G}\right)$.

In this case, if the government chooses to deviate from $\lambda=\lambda^{\prime}$ to $\lambda=0$, this will also lead it to switch from $\gamma=1$ to $\gamma=0$. Thus, comparing

$$
\begin{aligned}
E\left[u_{G}\left(\lambda^{\prime}, \gamma=1\right)\right]= & \left(1-\lambda^{\prime}\right) t+p\left(\left(1-f\left(\lambda^{\prime} t\right)\right) \rho_{M}+f\left(\lambda^{\prime} t\right) \rho_{G}\right) R(t) \\
& +(1-p) \rho_{N G} R(t)
\end{aligned}
$$

to

$$
E\left[u_{G}(0, \gamma=0)\right]=t+\rho_{N G} R(t)
$$

we find that the government will choose $\lambda=\lambda^{\prime}$ in this case only if

$$
p\left(\left(1-f\left(\lambda^{\prime} t\right)\right) \rho_{M}+f\left(\lambda^{\prime} t\right) \rho_{G}-\rho_{N G}\right) R(t)>\lambda^{\prime} t .
$$

Otherwise it will choose $\lambda=0$.

We have established the conditions under which $\lambda^{\prime}$ is preferred to $\lambda=0$, conditioned on the firms hiring the mafia. Notice that the condition in equation (A7) is purely a function of parameters and the voting rule. Thus, for a fixed voting rule, the case where $\lambda^{\prime}$ is optimal and the case where $\lambda=0$ is optimal are mutually exclusive.

Now it remains to consider the consistency of these conditions with the conditions under which the mafia makes a demand. There are three possibilities. From equation (A4), if $k>(1-t)[(1-f(0)) /(p f(0))]$, then the mafia withdraws, making no demand. If so, the government never challenges, and so $\lambda=0$. If $k<(1-t)[(1-f(\lambda t)) /(p f(\lambda t))]$, then the mafia demands $\bar{\phi}$ and the firm pays; the government challenges and chooses $\lambda=\lambda^{\prime}$ if equation (A7) is satisfied and the government does not challenge and does not invest in law enforcement if it is not satisfied. Note that, given Lemma 6 , $\lim _{t \rightarrow 1}(1-t)\left[\left(1-f \lambda^{\prime} t\right) /\left(p f\left(\lambda^{\prime} t\right)\right)\right]=0$. This implies that for any $k>0$, there is some $\overline{\bar{t}}<1$ such that $k>(1-t)\left[\left(1-f \lambda^{\prime} t\right) /\left(p f\left(\lambda^{\prime} t\right)\right)\right]$ for all $t>\overline{\bar{t}}$. 
Thus, we need to consider the case

$$
k \in\left((1-\overline{\bar{t}}) \frac{1-f\left(\lambda^{\prime} \overline{\bar{t}}\right)}{p f\left(\lambda^{\prime} \overline{\bar{t}}\right)},(1-t) \frac{1-f(0)}{p f(0)}\right) .
$$

In this case, there is no pure strategy equilibrium.

Define the critical value $\hat{\lambda}$ as the choice of $\lambda$ such that the mafia is exactly indifferent between demanding $\bar{\phi}$ and making no demand.

$$
k=(1-t) \frac{1-f(\hat{\lambda} t)}{p f(\hat{\lambda} t)} .
$$

Let $\pi$ be the probability that the mafia makes no demand and $1-\pi$ be the probability that the mafia demands $\bar{\phi}$. Then, in equilibrium the mafia must choose this probability such that $\hat{\lambda}$ is optimal for the government. The government's expected utility is

$$
\begin{aligned}
E\left[u_{G}(\lambda \mid t, \pi)\right]= & (1-\lambda) t+\left[\pi \rho_{N M}+(1-\pi)\left(p \left((1-f(\lambda t)) \rho_{M}\right.\right.\right. \\
& \left.\left.\left.+f(\lambda t) \rho_{G}\right)+(1-p) \rho_{N G}\right)\right] R(t) .
\end{aligned}
$$

The mafia chooses $\pi$ such that the following holds:

$$
\pi=1-\frac{1}{p R(t) f^{\prime}(\hat{\lambda} t)\left(\rho_{G}-\rho_{M}\right)} .
$$

Combining all these cases, we can formally characterize the proportion of tax revenue invested in law enforcement in the following lemma:

Lemma 7. If $p\left(\left(\left(1-f\left(\lambda^{\prime} t\right)\right) \rho_{M}+f\left(\lambda^{\prime} t\right) \rho_{G}\right)-\rho_{N G}\right) R(t)>\lambda^{\prime} \overline{\bar{t}}$, then

$$
\lambda^{*}= \begin{cases}1 & \text { if } t \in[0, \overline{\bar{t}}] \text { and } f^{\prime}(t)>\frac{1}{p\left(\rho_{G}-\rho_{M}\right) R(t)} \\ \lambda^{\prime} & \text { if } t \in[0, \overline{\bar{t}}] \text { and } f^{\prime}(t) \leq \frac{1}{p\left(\rho_{G}-\rho_{M}\right) R(t)} \\ \hat{\lambda} & \text { if } t \in\left(\overline{\bar{t}}, 1-p k \frac{f(0)}{1-f(0)}\right) \\ 0 & \text { if } t>1-p k \frac{f(0)}{1-f(0)}\end{cases}
$$

where $\lambda^{\prime}$ and $\hat{\lambda}$ are implicitly defined by equations (A6) and (A8), respectively. rates.

If $p\left(\left(\left(1-f\left(\lambda^{\prime} t\right)\right) \rho_{M}+f\left(\lambda^{\prime} t\right) \rho_{G}\right)-\rho_{N G}\right) R(t)<\lambda^{\prime} \overline{\bar{t}}$, then $\lambda^{*}=0$ for all tax 
Proof. The proof follows from the preceding derivation.

\section{A.7 Proof of Proposition 1}

The optimal government resource investment is given by equation (A10).

We will make use of the following result.

Lemma 8. $\hat{\lambda} t$ is decreasing in $t$.

Proof. From equation (A8), $[f /(1-f)](\hat{\lambda} t)=(1-t) /(p k)$. Because the right-hand side is obviously decreasing in $t$, the left-hand side must be as well. Define $g(\cdot)=[f /(1-f)](\cdot)$. Then $g^{\prime}=\left[f^{\prime} /(1-f)\right]+\left[f f^{\prime} /(1-f)^{2}\right]$ $>0$. Thus, in order for the left-hand side to be decreasing in $t, \hat{\lambda} t$ must be decreasing in $t$.

If $t \in[0, \overline{\bar{t}}]$, then $\lambda^{*} t$ is equal either to $\lambda^{\prime} t$ or $t$. Clearly, the latter is increasing in $t$ and the former is increasing in $t$ by Lemma 6 . If

$$
t \in\left(\overline{\bar{t}}, 1-p k \frac{f(0)}{1-f(0)}\right),
$$

then $\lambda^{*} t=\hat{\lambda} t$, which is decreasing in $t$ by Lemma 8 . If

$$
t>1-p k \frac{f(0)}{1-f(0)},
$$

then $\lambda^{*} t=0$, which is constant in $t$.

\section{A.8 Proof of Proposition 2}

From equation (A4), if $t<\overline{\bar{t}}$, the mafia demands $\bar{\phi}$. If

$$
t \in\left(\overline{\bar{t}}, 1-p k \frac{f(0)}{1-f(0)}\right),
$$

the mafia demands $\bar{\phi}$ with probability $1-\pi$, where $\pi$ is given by equation (A9). From the concavity of $f, f^{\prime \prime}<0$ and from Lemma $8,(\partial \hat{\lambda} t / \partial t)<0$; it follows that

$$
\frac{\partial \pi}{\partial t}=\frac{f^{\prime \prime}(\hat{\lambda} t) \frac{\partial \hat{\lambda} t}{\partial t}}{p\left(\rho_{G}-\rho_{M}\right) R(t)\left(f^{\prime}(\hat{\lambda} t)\right)^{2}}>0,
$$

and hence $1-\pi$ is decreasing in $t$. By equation (A4) if $t>1-$ $p k[f(0) /(1-f(0))]$, the mafia makes no demand. 


\section{A.9 Proof of Remark 1}

From the argument in the text, the firm wants to maximize $\rho_{G}-\rho_{M}$ subject to the constraint that the government challenge the mafia. From section A.6, when $\rho_{G}=1$ and $\rho_{M}=0$, the government will challenge if either $\rho_{N G}<f(0)$ or $p\left(f\left(\lambda^{\prime} t\right)-\rho_{N G}\right) R>\lambda^{\prime} t$. Taken together, this implies the firm will choose

$$
\rho_{N G}<\max \left\{f(0), f\left(\lambda^{*} t\right)-\frac{\lambda^{*} t}{p R}\right\} .
$$

Doing so is always possible because $f(0)>0$.

\section{A.10 Proof of Proposition 3}

First consider the case in which the firm has refused to pay off the mafia. Absent a bribe, the firm wants the government to challenge the mafia, which it can induce it to do by choosing the re-election probabilities $\rho_{R N G}, \rho_{R G}$, and $\rho_{R M}$ properly. As such, the mafia's expected payoff from not paying the bribe is $(1-f(\widetilde{\tilde{\lambda}} t))(1-t)-f(\widetilde{\widetilde{\lambda}} t) k$. The mafia's payoff from paying the bribe is $1-t-\beta_{R}$. Hence, the mafia is willing to pay the bribe if

$$
\beta_{R} \leq f(\widetilde{\tilde{\lambda}} t)(1-t+k) .
$$

If the government demands a bribe it chooses the highest bribe that will be paid [i.e. $\left.\beta_{R}=f(\widetilde{\tilde{\lambda}} t)(1-t+k)\right]$. This implies that the government's expected payoff from demanding a bribe is $f(\widetilde{\widetilde{\lambda}} t)(1-t+k)+\rho_{R N G} R(t)$, while its expected payoff from challenging the mafia is $\left(f(\lambda t) \rho_{R G}+(1-\right.$ $\left.f(\lambda t)) \rho_{R M}\right) R(t)$. It chooses the action that yields the higher payoff.

The firm, having refused to pay off the mafia, strictly prefers for the government to challenge. To achieve this, it must choose a re-election rule that simultaneously satisfies

$$
f(\lambda t) \rho_{R G}+(1-f(\lambda t)) \rho_{R M} \geq \rho_{R N G}
$$

(so the government will consider challenging) and

$$
f(\widetilde{\tilde{\lambda}} t)(1-t+k)+\rho_{R N G} R(t) \leq\left(f(\lambda t) \rho_{R G}+(1-f(\lambda t)) \rho_{R M}\right) R(t)
$$

(so the government will prefer to challenge rather than accept a bribe). It is feasible to do this if and only if

$$
f(\widetilde{\tilde{\lambda}} t)(1-t+k) \leq R(t) .
$$

Next consider the case in which the firm has paid off the mafia and the government has discovered the mafia's activities. Here, as in the original model, once the firm has paid the mafia's fee, it is indifferent about whether or not the government challenges (of course, it will care earlier in the game 
because this will affect the government's investment decision). The government will challenge if $f(\lambda t) \rho_{G}+(1-f(\lambda t)) \rho_{M} \geq \rho_{N G}$.

If the mafia expects that the government will not challenge should it refuse to pay a bribe, then the mafia will be unwilling to pay any bribe. If, however, the mafia anticipates that the government will challenge if not bribed, then the mafia will be willing to pay a bribe if $\beta_{P} \leq f(\widetilde{\tilde{\lambda}} t) k$ (i.e. the cost of the bribe is less than the expected cost of conflict). The government, if it demands a bribe, will demand the highest bribe the mafia will pay $\beta_{p}=$ $f(\widetilde{\widetilde{\lambda}} t) k$.

Given all of this, what fee will the mafia demand of the firm? Condition (13) demonstrates that, if $f(\widetilde{\tilde{\lambda}} t)(1-t+k)>R(t)$, then the firm is unable to induce the government to challenge. In this case, the mafia can extract everything in fees (i.e. $\phi=1-t$ ).

If, however, $f(\widetilde{\tilde{\lambda}} t)(1-t+k) \leq R(t)$, then the firm can induce the government to challenge when the firm has refused to pay the mafia. As such, the firm is only willing to pay a fee such that $\phi \leq(1-f(\widetilde{\tilde{\lambda}} t))(1-t)$.

Given this, there are two cases to consider in determining what the mafia will do. First, consider the case where the mafia anticipates that if the firm pays the mafia and the government becomes aware of its activities it will challenge. In this case, the mafia understands that with probability $p$ either it will enter into conflict with the government [with an expected loss of $f(\widetilde{\tilde{\lambda}} t) k$ ] or it will have to bribe the government [again, with cost $f(\widetilde{\tilde{\lambda}} t) k]$. In either event, the mafia will choose to make a demand of the firm, rather than exit the market, if

$$
(1-f(\tilde{\lambda} t))(1-t)-p f(\tilde{\tilde{\lambda}} t) k \geq 0 .
$$

Second, consider the case where the mafia anticipates that if the firm pays the mafia and the government becomes aware of the mafia's activities, the government will not challenge. In this case, the mafia will demand a fee, rather than exit the market, if

$$
(1-f(\tilde{\lambda} t))(1-t) \geq 0 .
$$

The firm wants the government's investment in law enforcement to be as high as possible, because this decreases both the probability the firm will have to pay the mafia and the size of the fee if it does have to pay the mafia. As before, the government will not invest at all if it does not anticipate challenging the mafia. Thus, the firm's first priority is to convince the government to challenge after the firm has paid off the mafia. That is, the firm must choose a re-election rule such that condition (2) holds. Once the firm has successfully deterred bribery, it also wants its electoral rule to give the government incentives to invest in law enforcement. 
If $R(t)>k$, then $\rho_{G}=1, \rho_{M}=\rho_{N M}=0$ guarantees that (2) holds (and thus, bribery does not occur) and that the government has the highest incentives to invest in law enforcement. If $R(t) \in(k f(0), k)$ then $\rho_{G}=1, \rho_{N G}=0$, and $\rho_{M}$ is the lowest value that insures the satisfaction of (2) and so that bribery does not occur. That value in equilibrium (thus, dropping the belief notation on $\lambda$ ) is

$$
\rho_{M}=\left(\frac{k}{R(t)}-1\right) \frac{f(\lambda t)}{1-f(\lambda t)} .
$$

Because $k>R(t), \rho_{M}>0$. Because $\rho_{G}>\rho_{M}$ and the government challenges the mafia in equilibrium, the government has incentive to choose $\lambda>0$. In particular, government maximizes

$$
\begin{aligned}
E\left[u^{G}(\cdot)\right]= & (1-\lambda) t+\left[p(1-f(\lambda t)) \rho_{M}+p f(\lambda t) \rho_{G}\right. \\
& \left.+(1-p) \rho_{N G}\right] R(t) .
\end{aligned}
$$

The first-order condition is

$$
-t+\left[-p f^{\prime}(\lambda t) t \rho_{M}+p f^{\prime}(\lambda t) t \rho_{G}\right] R(t)=0 .
$$

Solving for $\lambda$, we get

$$
\lambda=\frac{1}{t}\left(f^{-1}\right)^{\prime} \frac{1}{p R(t)\left(\rho_{G}-\rho_{M}\right)}>0 .
$$

If $R(t)<k f(0)$, then $\forall \rho$ (including $\rho_{G}=\rho_{M}=1, \rho_{N G}=0$ ), condition (2) holds.

\section{A.11 Proof of Proposition 4}

The left-hand side of equation (A4), evaluated at $\gamma=0$, is always less than the right-hand side, hence the first part of Lemma 4 describes the optimal choice of $\phi$. On the equilibrium path, $\phi=\bar{\phi}$, and the firm pays off the mafia. This implies that the government never engages in law enforcement. Hence, the government has no incentive to invest in law enforcement $\left(\lambda^{*}=0\right.$, for all $\rho$ ), which means that any revenues spent on taxes will be misappropriated.

\section{ACKNOWLEDGMENTS}

We have benefited from comments by Scott Ashworth, Ernesto Dal Bó, Dimitri Landa, Marco Manacorda, Massimo Morelli, and seminar participants at Berkeley, Harvard, and the University of Chicago. 


\section{REFERENCES}

Alexeev, M., E. Janeba, and S. Osborne, 2003, Taxation and evasion in the presence of extortion by organized crime. Mimeo, Department of Economics, Indiana University.

Austen-Smith, D. and J. Banks, 1989, Electoral accountability and incumbency, in: P. C. Ordeshook, ed., Models of Strategic Choice in Politics (University of Michigan Press, Ann Arbor, MI) 121-148.

Baccara, M. and H. Bar-Isaac, 2005, Crime, punishment, and organizational structure. Mimeo, Stern School of Business, New York University.

Bandeira, O., 2003, Land reform, the market for protection, and the origins of the Sicilian mafia: theory and evidence. Journal of Law, Economics, and Organization 19, 218-244.

Bardhan, P., 1997, Corruption and development: a review of issues. Journal of Economic Literature 35, 1320-1346.

Barro, R., 1973, The control of politicians: an economic model. Public Choice 14, $19-42$.

Basu, K., S. Bhattacharya, and A. Mishra, 1992, Notes on bribery and the control of corruption. Journal of Public Economics 48, 349-359.

Bowles, R. and N. Garoupa, 1997, Casual police corruption and the economics of crime. International Review of Law and Economics 17, 75-87.

Braguinsky, S., 1999, Enforcement of property rights during the Russian transition: problems and some approaches to a new liberal solution. Journal of Legal Studies 28, 515-544.

Dal Bó, E., P. Dal Bó, and R. Di Tella, 2006, "Plata o Plomo?": bribe and punishment in a theory of political influence. American Political Science Review 100, $41-53$.

Ferejohn, J., 1986, Incumbent performance and electoral control. Public Choice 50, $5-26$.

Frye, T. and E. Zhuravskaya, 2000, Rackets, regulation, and the rule of law. Journal of Law, Economics, and Organization 16, 478-502.

Gambetta, D., 1993, The Sicilian Mafia: The Business of Private Protection (Harvard University Press, Cambridge, MA).

— - and P. Reuter, 1995, Conspiracy among the many: the mafia in legitimate industries, in: G. Fiorentini and S. Peltzman, eds., The Economics of Organized Crime (Cambridge University Press, Cambridge, UK) 116-135.

Gaddy, C. G. and W. G. Gale, 2005, Demythologizing the Russian flat tax. Tax Notes International, March 14.

Garoupa, N. and M. Jellal, 2002, Information, corrruption, and optimal law enforcement. CEPR Discussion Paper.

Gehlbach, S., 2007, Revenue traps. Economics and Politics 19, 73-96.

Grossman, H., 1995, Rival kleptocrats: the mafia vs. the state, in: G. Fiorentini and S. Pelzman, eds., The Economics of Organised Crime (Cambridge University Press, Cambridge, UK) 143-160.

Hafer, C., 2006, On the origins of property rights: conflict and production in the state of nature. Review of Economic Studies 73, 119-143.

Hay, J. R. and A. Shleifer, 1998, Private enforcement of public laws: a theory of legal reform. American Economic Review 88, 398-403.

Johnson, S., D. Kaufmann, and A. Shleifer, 1997, The unofficial economy in transition. Brookings Papers on Economic Activity 2, 159-239.

Konrad, K. and S. Skaperdas, 1998, Extortion. Economica 65, 461-477. 
and -1999 , The market for protection and the origin of the state. CEPR Discussion Paper No. 2173.

Kugler, M., T. Verdier, and Y. Zenou, 2005, Organized crime, corruption, and punishment. Journal of Public Economics 89, 1639-1663.

Polinsky, A. M. and S. Shavell, 2001, Corruption and optimal law enforcement. Journal of Pubic Economics 81, 1-24.

Schelling, T., 1984, What is the business of organized crime?, in: T. Schelling, ed., Choice and Consequence (Harvard University Press, Cambridge, MA) 179-194.

Shleifer, A. and D. Treisman, 2000, Without a Map: Political Tactics and Economic Reform in Russia (MIT Press, Cambridge, MA). 617.

Skaperdas, S., 1992, Cooperation, conflict, and power in the absence of property rights. American Economic Review 82, 720-739.

$\longrightarrow, 2001$, The political economy of organized crime: providing protection when the state does not. Economics of Governance 2, 173-202.

Smith, A. and F. Varese, 2001, Payment, protection and punishment: the role of information and reputation in the mafia. Rationality and Society 13, 349-393.

Sokolov, V., 2004, From guns to briefcases: the evolution of Russian organized crime. World Policy Journal 21, 68-74.

Sonin, K., 2003, Why the rich may favor poor protection of property rights. Journal of Comparative Economics 31, 715-731.

Tilly, C., 1985, War making and state making as organized crime, in: P. B. Evans, D. Rueschemeyer, and T. Skocpol, eds., Bringing the State Back In (Cambridge University Press, Cambridge, UK) 169-187.

Varese, F., 2001, The Russian Mafia: Private Protection in a New Market Economy (Oxford University Press, Oxford, UK). 